\title{
An Exploratory Study on Enhancing University Students' Network Moral identity through Moral Sensitivity Training
}

\author{
Xiaofeng Guan \\ Faculty of Science \\ East China Jiaotong University \\ Nanchang, China
}

\author{
Baoquan Wei \\ Institute of Electrical and Engineering \\ East China Jiaotong University \\ Nanchang, China
}

\begin{abstract}
Based on the analysis of the status quo of students' network moral education from science and engineering university. By means of defining the sensitive concept of network morality as well as the value analysis of sensitive theory of network morality, we could, in the process of developing network morality ,enhance the students' identity of network morality through making full use of the context model. The model aims to develop and simulate their sensitivity of network morality, guide them to cognize actively, give a full play of their initiative and advance the ability to select views. The students should be in accordance with the excellent moral requirements to practice their own action consciously so as to enhance the scientificity and effectiveness of the work of moral education.
\end{abstract}

Keywords-moral sensitivity training; college students; network morality

\section{INTRODUCTION}

The thirty-eighth statistics report of China's Internet network development released by China Internet Network Information Center shows, by the end of June 2016, the number of China's internet users reached 7.1 billion, the internet users on mobile phones reached 656 million, accounted for $92.5 \%$ of the total number of internet users, which exceeded the number of original computer terminal Internet users and now ranks first in the internet terminals .The students are still the largest groups of Internet users in China, accounting for $25.1 \%$ of total number of internet users. Mobile Internet promote the overall development of the Internet, which make Internet users life comprehensively Networking. Network era has brought both opportunities and challenges. The positive side of it is the mass information, the concept of equality and the fast-spread information, also the negative side information clutter, lack of reason and regulatory difficulties. The phenomenon of Scarcity of Network ethics has occurred from time to time, and it is becoming a more and more prominent problem of social ethics in our country, which requires our initiative to dominate the network field to advocate healthy themes on the Internet.

Moral sensitivity is an important concept of Neo

Fund project: in 2014, Jiangxi College humanities and social science research (special) ideological and political education subject (SZZX1411) 2014 East China jiaotong university scientific research funds (14LX04). kohlbergian orientation. It is initial composition of logical psychology prior to the occurrence of moral behavior and is the moral understanding and interpretation of situation, which typically reflect the interaction between moral cognition and moral emotion. Network moral sensitivity refers to the sensitiveness to the network moral situation. It is people' $s$ feelings towards the network moral factors and implicit morality. The concept of the network moral sensitivity training camp is put forward based on the mode of traditional undergraduate ideological and political education. It dose not aim to instill the students a set of prearranged strict values, but that, through a certain process, let students reflect on their own life and be responsible for their own behaviors, thus clarifying their own values, establishing College Students' morality network adapted to the internet era, which could develop their morality selection.

\section{MORAL SENSITIVITY TRAINING NECESSITY FOR ENHANCING THE VALUE OF COLLEGE STUDENTS' NETWORK MORAL IDENTITY}

It is necessary to improve college students' network moral identity through moral sensitivity training. The reasons are as follows.

\section{A. Adapting to the New Situation and Promoting the} Transformation from the Dialogue Network Moral Education to Communicative Network Moral Education

With the advancement of the times and the development of information network, the ideological environment is going through major changes, so is the situation of the network moral education object. At present, most of the theoretic development of domestic network moral education is still at the stage of one-way outputting. Cramming method of teaching is difficult to fit contemporary college students' psychological changes. The main form of sensitive training camp of network morality is the communicative dialogue, this is not the form which is only standard-oriented, but pay attention to cultivating students' creative ideas and attach great importance to sharing students' thinking and life experience in the teaching practice. It requires systematic study the theoretic fruits of generality of Mao 
Zedong Thoughts, Marxist Theory and Chinese Marxism, as well as the firm ideals and beliefs, the spirit of respecting science, rich imagination and the courage to dare to criticize. Therefore, it can teach students dialectical and critical thinking so as to improve their awareness of investigation and research and the ability to solve practical problems. Through the cultivation of their innovative spirit and critical consciousness, we would realize the transformation from moral education to the emotional education, from the direction of the one-way education to the two-way interactive communication, which lead to the enhancement of the effectiveness of moral education.

\section{B. Follow the Law of Education and Pay Attention to the Healthy Growth of College Students}

University is not only the period to learn knowledge and skills, but also the fundamental time of forming outlook of world, life and value. The standard of College Students' growth and development is not only having the scientific and cultural knowledge, but also a strong physique, healthy mentality and good quality of self-control. Students are the largest groups of Chinese Internet users, they are active in thinking and get easy to accept new things. In this open and all-dimensional global network society, they have a very strong sense of participation of it. Educational practice has turned out that the influence of the ideological and political quality of a person is huge, which is related to the students comprehensive development. We must understand the puzzlement and problems that college students are prone to be faced with in the course of development, help them to effectively solve these pertinent problems, as well as guide them to build advanced ideological and political quality and cultivate fine morality so as to realize their comprehensive and balanced development, thus become the qualified builders and reliable successors of socialism with Chinese characteristics.

\section{From the Situation at Home and Abroad, College Students' Network Moral Construction Is A Matter of National Prospects and National Destiny}

At present, the domestic and international situation is complicated. With the rapid growth of the information industry, various ideological and cultural affect each other. Reactionary forces at both home and abroad have increased the ideological infiltration and competition of young students. They will be under the banner of a variety of banners to hide their real purpose. For example, they will capitalize on academic research, religious ceremonies, etc. to appeal to students; make use of social contradictions in the current transition period, such as the widening gap between the rich and the poor, difficulties of college students employment and so on, to defy the guidelines and policies of party; and spread false news through QQ, microblog and other new media. College students are so young and less-experienced, as a result, the thought and character are not enough mature. They are easy to be drawn and capitalized on by hostile forces. However, college students are the pillars of our motherland and the future and hope of our nation. They should have a firm belief in Marxism. Only in this way can we ensure the smooth development of our country and nation. Therefore, we should strengthen the establishment of College Students' network morality, and help them to establish the ideal and belief of socialism with Chinese characteristics.

\section{THE POSSIBILITY TO ENHANCE IDENTITY VALUE OF COLlEgE STUdents' NeTWORK MORALITY THROUGH MORAL SENSITIVITY TRAINING}

It is possible to improve college students' network moral identity through the moral sensitivity training, and it based on any of the following three aspects.

\section{A. Coexistence of Freedom and Norm}

Network is not only a virtual world, but also another reality world. Due to the substantial changes of basis of social life, the way of people' $\mathrm{s}$ interaction and activities, especially the adjustment of the interests in the process of reforms, changes also occur among people's ideological concept, moral emotion and value orientation, which, what' $\mathrm{s}$ more, produce some new moral requirements. In the network world, it also need some relevant network ethics to Control people's behavior in the network society within the required range. Standardization of the network order requires perfect law, the strict law enforcement, positive publicity and the whole nation' $\mathrm{s}$ consciousness. The online world is free, and free speech is our right. However, the network freedom is not absolute, it always complement each other with standardization. Netizens need necessary standardizations. That' $s$ to say, their loss of some freedom is for maximum relative freedom and of the interests is for safeguarding the fundamental interests.

\section{B. Coexistence of Explicitness and Implicitness}

College students are dynamic and innovative groups. They are swift and sensitive to external stimuli. Their emotions would often appear on their face. Therefore, college students are endowed with characteristics of explicitness. However, college students' emotional appearance is not always consistent with their inner experience. In the network world where symbol is viewed as the identity, the dependent relations between people is replaced by the relations between people and network. Some college students will hide or control their true feelings, they will not behave casually just like that in their childhood. They sometimes will behave implicitly and reservedly, which is the result of the college students' conscious controls and unconscious defenses, and it is the two different things from hypocrisy. Yet the purpose of network moral sensitivity training is, through some a training, to enhance Internet users' feeling towards network moral situations, network moral factors and implicit moral.

\section{Coexistence of Complexity and Variability}

The development of college students' emotional psychology is both hierarchical and overlapped. Hierarchy embodies differences in emotions of college student in different ages (grades). On the one hand, with advancement 
of age, grade and rich social emotion, college students appear to be more care for people and the society and think more positively towards life. What' s more, their emotional stability, volatility and conflict will be strengthened during this period. On the other hand, different individuals vary to some degree in emotional development and emotional performance. Both Men and women's emotion have their own features, and the emotion of college students has a transitional characteristics, which possesses innocence and simpleness which is left from the childhood and adolescent and deliberation from adulthood.

\section{PRACTICALITY OF ENHANCING THE IDENTITY VALUE OF COLLEGE STUdENTS' NETWORK MORALITY THROUGH MORAL SENSITIVITY TRAINING}

Through moral sensitivity training, improvement would be achieved in college students' network moral identity. We should grasp the following several aspects at a practical level.

\section{A. Creating Situation of Online Conflicts and Trying Teaching Method of Empathy Experience}

The concept of empathy experience is significant in the development of moral understanding. Empathy is not only a consulting skill, but also a kind of personal qualities that make one be an Internet user naturally and make these qualities be the part of personality. Empathy is not only related to one' $\mathrm{s}$ talents, but also their training and cultivation. In the process of moral sensitivity training, through creating conflict situation of network, we could make certain virtual processing of typical materials of college students' real experience, or moral problems and moral events in the network life. In accordance with requirements of the education, we could process the materials into various dynamic and vivid expression forms, which can highlights the conflict situation. It help induce students to think actively, spur their awareness of plausible reasoning and encourage students to effectively cope with problems. College students' thinking on virtual network situation through their own network thought can contribute to produce moral action.

\section{B. Laying the Emphasizes on the Training of Hypothetical Deduction and Enhancing the Ability to Views Selecting}

Individual view-selecting ability is an essential condition of individual morality development. The growth of individual morality level is closely knitted with their own view-selecting ability. The establishment of selecting ability to fine social views can help promote individual moral socialization process. Network is a world of freedom and openness. It provide people with a big stage to communicate with one another. However, there are also many unfavorable hidden factors, which heavily challenge the college students' network morality. Various social contradictions and problems overlap and appear intensively. The independence, selectivity, variability and diversity of people' s thought activity have significantly increased. In the field of ideology, there appearing some significant phenomenon. All those requires us to proceed from the students' cognition. We should establish reasonable real conflict situation and strengthen the ability of the plausible reasoning, which could help students find laws and obtain new knowledge, so as to improve the students' moral behavior and the actual effect of school morality education.

\section{Doing A Good Job of Public Opinion Guidance and Enhancing the Value-screening Ability}

The current network environment where whether the good or the bad are intermingled is so poor. All kinds of information are filled on the internet. It is still difficult for adults to discern the authenticity of the information, let alone college students who are at lowness in self-controlling and discriminating. If lacking correct guidance, the students may get lost in their network life. This require them, under the guidance of socialist core values, to attain scientific analysis, correct answers and effective guidance for social hot issues. Correctly handle the interest relationship among the state, the collective and individual well. We must recognize the objective situation and treat problem rationally. We should service people as well as guide them at the same time. It is advisable to apply to all kinds of methods, like peer training, expert interview, equal discussion, self education, for guiding hotspot issues well from multiple perspectives and promoting the problem to be solved finally.

\section{CONCLUSION}

Era of value pluralism, means that we should pay close attention to students from the true sense of network moral education.In the network moral education, teachers only pay great attention to the cultivation of the students' moral thinking and moral sensitivity, in order to make students in a pluralistic society and the value of the brilliant at any time before the moral conflict make conscious moral judgment and moral reasoning and moral choice, can in a positive state of mind to build a community of life.

\section{REFERENCES}

[1] Zheng Xinjun Cen Guozhen. The research status and prospect of moral sensitivity. Psychological science progress [J]. 2007 (1).

[2] Zheng Xinjun CenGuoZhen. Moral sensitivity: conceptual understanding and analysis. New [J]. Journal of psychology, 2009 (01).

[3] Yuan Xiaolin, Xiao Shaobei progress of the theory of western mora judgment model. Foreign primary and secondary school education [J] 2009 (8).

[4] Zou Ling. Liu Guoxiong Individual moral sensitivity of measuremen and its enlightenments to education. The social psychological science [J]. 2013 (04).

[5] Rest J R. Moral development: Advance in research and theory. New York: A division of Greeenwood Press, 1986: 2 18.

[6] Rest J R, Narvaze D, Bebeau M J, Thoma S J.Postconventional mora thinking: a neo-Kohlbergian approach. New Jersey: Lawrence Erlbaum Associates Press, 1999. 101 102. 